\title{
ON GLOBAL IN TIME SOLUTIONS FOR DIFFERENTIAL-ALGEBRAIC EQUATIONS
}

\author{
Yu.E. Gliklikh, Voronezh State University, Voronezh, Russian Federation, \\ yeg@math.vsu.ru
}

We investigate differential-algebraic equations arising in mathematical models that describe some radio-technical devises. A class of differential-algebraic equations is described, for which necessary and sufficient conditions for global in time existence of solutions are proved. As well as in many papers where sufficient conditions for such equations are obtained, we reduce them to ordinary differential equations and then apply the necessary and sufficient conditions for the latter. We deal with the systems whose matrix pencil is regular and (for simplicity) the characteristic polynomial satisfies the rank-degree condition. We also require some additional conditions that allow us to reduce the differential-algebraic system to ordinary differential one.

Keywords: differential-algebraic equation; global existence of solution; proper function; complete Riemannian metric.

\section{Introduction}

In this paper we deal with the differential-algebraic equations of the form

$$
\tilde{L} \dot{x}(t)=\tilde{M} x(t)+\tilde{f}(t, x(t))
$$

in $\mathbb{R}^{n}$ where $\tilde{L}$ and $\tilde{M}$ are $n \times n$ constant matrices ( $\tilde{L}$ is degenerate and $\tilde{M}$ is non-degenerate) and $\tilde{f}(t, x)$ is a vector field on $\mathbb{R}^{n}$.

Such equations arise in mathematical models describing some radio-technical devises (see [1-3]). In [3-5] (see also the bibliography therein) some sufficient conditions for global in time existence of solutions of differential-algebraic systems are obtained. In many cases the idea of the proof is to reduce a differential-algebraic equation to an ordinary differential equation by some artificial machinery and then to apply criteria for existence of global in time solutions for the latter, reformulated in terms of the system under consideration.

The main aim of this paper is to obtain necessary and sufficient conditions for existence of global in time solutions for some type of differential-algebraic equations . We use similar idea of reducing them to ordinary differential equations but after that we apply the necessary and sufficient results obtained in [6-8].

For the sake of simplicity of presentation of our methods, unlike [3-5], we do not use spectral projectors, etc., but first we transform the differential-algebraic equation to its canonical form and then formulate the existence theorems in the terms of the latter. Also for the sake of simplicity, we deal only with the systems with regular matrix pencil whose characteristic polynomial satisfies the rank-degree condition (Chistyakov's condition). We prove the necessary and sufficient conditions for a subclass of the above-mentioned systems satisfying some conditions similar to those in [5].

The case where the rank-degree condition is not assumed, can be investigated as well, but it requires additional difficulties in its presentation and we suppose to consider it in forthcoming publications. 


\section{Preliminaries}

Consider the ordinary differential equation

$$
\dot{x}(t)=X(t, x(t))
$$

with smooth right-hand side on a smooth finite-dimensional manifold $M$. Introduce the enlarged phase space $M^{+}=\mathbb{R} \times M$ and the vector field $X^{+}$on it that at the point $(t, x) \in M^{+}$is given by the formula $X_{(t, x)}^{+}=(1, X(t, x))$.

A smooth function $f: M^{+} \rightarrow \mathbb{R}$ is called proper if its preimage of every compact set in $\mathbb{R}$ is compact in $\mathrm{M}^{+}$. Note that in a Euclidean space, a function $f$ is proper if and only if $f(x) \rightarrow \infty$ as $x \rightarrow \infty$.

The derivative of a function $f$ in the direction of the vector field $X^{+}$is denoted by $X^{+} f$.

Recall that a Riemannian metric is given on a manifold $N$ if in every tangent space $T_{m} N$ an inner product $\langle\cdot, \cdot\rangle_{m}$ is given such that the family of inner products is smooth in $m$. The norm of a vector $Y \in T_{m} N$ is defined by usual formula $\|Y\|=\sqrt{\langle Y, Y\rangle_{m}}$. The Riemannian metric determines the Riemannian distance $\rho\left(m_{0}, m_{1}\right)$ as the infinum of length of curves connecting $m_{0}$ and $m_{1}$ in $N$. With respect to this distance, the Riemannian manifold turns to a metric space. The Riemannian metric is called complete, if the abovementioned metric space is complete.

In two theorems below the role of manifold $N$ is played by $M^{+}$introduced above.

Theorem 1. [6-8] All solutions of (2) exist on the entire real line $t \in(-\infty,+\infty)$ if and only if on $M^{+}$there exists a complete Riemannian metric such that the norm $\left\|X^{+}\right\|$of vector field $X^{+}$is uniformly bounded on $M^{+}$.

Theorem 2. [7,8] All solutions of (2) exist on the entire real line $t \in(-\infty,+\infty)$ if and only if there exists a smooth proper function $\varphi: M^{+} \rightarrow \mathbb{R}$ such that the absolute value $\left|X^{+} \varphi\right|$ of the derivative of $\varphi$ in the direction of $X^{+}$is uniformly bounded on $M^{+}$.

We need also some facts from the theory of matrices. Detailed explanation of this material can be found, e.g., in $[9,10]$.

Definition 1. Let two $n \times n$ constant matrices $A$ and $B$ be given. The expression $\lambda A+B$ where $\lambda$ is a real or complex valued parameter, is called the matrix pencil. The polynomial $\operatorname{det}(\lambda A+B)$ (with respect to $\lambda$ ) is called the characteristic polynomial of the pencil. If $\operatorname{det}(\lambda A+B)$ is not identical zero, the pencil is called regular.

Theorem 3. Let the matrix pencil $\lambda A+B$ be regular. Then there exist non-degenerate matrices $P$ and $Q$ such that

$$
P(\lambda A+B) Q=\lambda\left(\begin{array}{cc}
E_{d} & 0 \\
0 & N
\end{array}\right)+\left(\begin{array}{cc}
J & 0 \\
0 & E_{n-d}
\end{array}\right)
$$

where $E_{d}$ and $E_{n-d}$ are unit matrices of the corresponding dimensions, $N$ is an upper triangle matrix consisting of Jordan boxes with zeros on diagonal and $J$ is a certain $d \times d$ block. 
Definition 2. If the characteristic polynomial satisfies the equality

$$
\operatorname{rank}(A)=\operatorname{deg}(\operatorname{det}(\lambda A+B))
$$

we say that the polynomial satisfies the condition rank-degree (Chistyakov's condition).

Theorem 4. If the characteristic polynomial satisfies the rank-degree condition, assertion of Theorem 3 holds true and formula (3) takes the form

$$
P(\lambda A+B) Q=\lambda\left(\begin{array}{cc}
E_{d} & 0 \\
0 & 0
\end{array}\right)+\left(\begin{array}{cc}
J & 0 \\
0 & E_{n-d}
\end{array}\right) .
$$

\section{The Main Results}

Consider equation (1) such that the pencil $\lambda A+B$ is regular and its characteristic polynomial satisfies the rang-degree condition. Then applying the matrices $P$ and $Q$ from Theorem 3, by Theorem 4 we reduce (1) to the form

$$
L \dot{y}(t)=M y(t)+f(t, y(t))
$$

where $L=P \tilde{L} Q, M=P \tilde{M} Q, y(t)=Q^{-1} x(t)$ and $f(t, y(t))=P \tilde{f}\left(t, Q^{-1} x(t)\right)$.

The block structure of the matrices in (5) determines the decomposition of $\mathbb{R}^{n}$ into the direct sum $\mathbb{R}^{n}=\mathbb{R}^{d} \oplus \mathbb{R}^{n-d}$. Using this decomposition, let us also decompose every vector $y \in \mathbb{R}^{n}$ into the pair $y=y^{(1)}+y^{(2)}$ where $y^{(1)} \in \mathbb{R}^{d}$ and $y^{(2)} \in \mathbb{R}^{n-d}$, and vector $f(t, y)$ into $f(t, y)=f^{(1)}\left(t, y^{(1)}+y^{(2)}\right)+f^{(2)}\left(t, y^{(1)}+y^{(2)}\right)$ where $f^{(1)}\left(t, y^{(1)}+y^{(2)}\right) \in \mathbb{R}^{d}$ and $f^{(2)}\left(t, y^{(1)}+y^{(2)}\right) \in \mathbb{R}^{n-d}$. Taking into account formula (5), after that we can rewrite (6) in the form

$$
\left(\begin{array}{cc}
E_{d} & 0 \\
0 & 0
\end{array}\right)\left(\begin{array}{c}
\dot{y}^{(1)}(t) \\
\dot{y}^{(2)}(t)
\end{array}\right)=\left(\begin{array}{cc}
J & 0 \\
0 & E_{n-d}
\end{array}\right)\left(\begin{array}{c}
y^{(1)}(t) \\
y^{(2)}(t)
\end{array}\right)+\left(\begin{array}{c}
f^{(1)}\left(t, y^{(1)}(t)+y^{(2)}(t)\right) \\
f^{(2)}\left(t, y^{(1)}(t)+y^{(2)}(t)\right)
\end{array}\right) .
$$

Equation (7) evidently can be presented as the system of differential and functional equations

$$
\left\{\begin{array}{l}
\dot{y}^{(1)}(t)=J y^{(1)}(t)+f^{(1)}\left(t, y^{(1)}(t)+y^{(2)}(t)\right) \\
y^{(2)}(t)+f^{(2)}\left(t, y^{(1)}(t)+y^{(2)}(t)\right)=0
\end{array} .\right.
$$

Condition 1. We suppose that for every point $\left(t, y^{(1)}\right) \in \mathbb{R} \times \mathbb{R}^{d}$ there exists a unique point $y^{(2)}=\Phi\left(t, y^{(1)}\right) \in \mathbb{R}^{n-d}$ that is smooth jointly in $\left(t, y^{(1)}\right)$ and such that $-f^{(2)}\left(t, y^{(1)}+\right.$ $\left.\Phi\left(t, y^{(1)}\right)\right)=\Phi\left(t, y^{(1)}\right)=y^{(2)}$.

Remark 1. Under Condition 1 one can easily see that $y^{(2)}=\Phi\left(t, y^{(1)}\right) \in \mathbb{R}^{n-d}$ is a unique fixed point of the operator $-f^{(2)}\left(t, y^{(1)}+(\cdot)\right): \mathbb{R}^{n-d} \rightarrow \mathbb{R}^{n-d}$. This fixed point exists, e.g., if $f^{(2)}\left(t, y^{(1)}+(\cdot)\right)$ is Lipschitz continuous, i.e., if there exists $k \in(0,1)$ such that for every pair of points $z_{1}, z_{2} \in \mathbb{R}^{n-d}$ and every $\left(t, y^{(1)}\right) \in \mathbb{R} \times \mathbb{R}^{d}$ the inequality $\left\|f^{(2)}\left(t, y^{(1)}+z_{1}\right)-f^{(2)}\left(t, y^{(1)}+z_{2}\right)\right\|<k\left\|z_{1}-z_{2}\right\|$ holds. Note that $k$ may be a smooth function depending on $\left(t, y^{(1)}\right)$. The fact that $y^{(2)}=\Phi\left(t, y^{(1)}\right) \in \mathbb{R}^{n-d}$ is smooth jointly in $\left(t, y^{(1)}\right)$ can be derived from the implicit function theorem. A condition of this sort in the language of functions $y^{(1)}(t)$ and $y^{(2)}(t)$ is used in [5]. 
If Condition 1 is satisfied, system (8) is equivalent to the equation

$$
\dot{y}^{(1)}(t)=J y^{(1)}(t)+f^{(1)}\left(t, y^{(1)}(t)+\Phi\left(t, y^{(1)}(t)\right)\right)
$$

in $\mathbb{R}^{d}$. Since the right-hand side of (9) is smooth, for every initial condition $y^{(1)}(0)=y_{0} \in$ $\mathbb{R}^{d}$ the equation has a unique (local) solution.

Condition 2. The function $f(t, x)$ is given as follows: for every $t \in \mathbb{R}$ and every $y=$ $y^{(1)}+y^{(2)} \in \mathbb{R}^{n}=\mathbb{R}^{d} \times \mathbb{R}^{n-d}$ the equality $f^{(2)}\left(t, y^{(1)}+y^{(2)}\right)=-y^{(2)}$ holds.

Under Condition 2 the situation is trivial. Nevertheless we investigate this case since Condition 2 is a very special example of Condition 1 and it allows us to obtain another sort of necessary and sufficient condition for global in time existence of solution. Under Condition 2 in system $(8)$ we set $y^{(2)}(t)=$ const and so reduce (8) to the system

$$
\left\{\begin{array}{l}
\dot{y}^{(1)}(t)=J y^{(1)}(t)+f^{(1)}\left(t, y^{(1)}(t)+y^{(2)}\right), \\
y^{(2)}=\text { const. }
\end{array}\right.
$$

in $\mathbb{R}^{n}$. Since the right-hand side of (10) is smooth, for every initial condition $y(0)=y_{0}=$ $y_{0}^{(1)}+y_{0}^{(2)}$ in $\mathbb{R}^{n}$ there exists a (local) solution of $(10)$.

In obtaining the necessary and suffitient conditions for global in time existence of solutions of (1), first we consider the case where Condition 1 is satisfied. Denote by $Y^{+}\left(t, y^{(1)}\right)$ the vector field $\left(1, J y^{(1)}+f^{(1)}\left(t, y^{(1)}+\Phi\left(t, y^{(1)}\right)\right)\right)$ in $\mathbb{R}^{d+1}$.

Theorem 5. Let the pencil $\lambda \tilde{L}+\tilde{M}$ be regular, the characteristic polynomial satisfy the rank-degree condition and Condition 1 be fulfilled. Then all solutions of (1) exist on $(-\infty,+\infty)$ if and only if there exists a complete Riemannian metric on $\mathbb{R}^{d+1}$ such that the norm of vector field $Y^{+}$is uniformly bounded on $\mathbb{R}^{d+1}$.

Theorem 6. Let the pencil $\lambda \tilde{L}+\tilde{M}$ be regular, the characteristic polynomial satisfy the rang-degree condition and Condition 1 be fulfilled. Then all solutions of (1) exist on $(-\infty,+\infty)$ if and only if on $\mathbb{R}^{d+1}$ there exists a smooth proper function $\varphi: \mathbb{R}^{d+1} \rightarrow \mathbb{R}$ such that the absolute value $\left|Y^{+} \varphi\right|$ of derivative of $\varphi$ in the direction of $Y^{+}$is uniformly bounded on $\mathbb{R}^{d+1}$.

Indeed, Theorem 5 (Theorem 6) is a reformulation of Theorem 1 (Theorem 2, respectively) for equation (9) on $\mathbb{R}^{d}$.

Now let us turn to the case, in which Condition 2 is satisfied. Here we introduce the vector field $\bar{Y}^{+}\left(t, y^{(1)}, y^{(2)}\right)=\left(1, J y^{(1)}(t)+f^{(1)}\left(t, y^{(1)}(t)+y^{(2)}\right), 0\right)$ on $\mathbb{R}^{n+1}$.

Theorem 7. Let the pencil $\lambda \tilde{L}+\tilde{M}$ be regular, the characteristic polynomial satisfy the rank-degree condition and Condition 2 be fulfilled. Then all solutions of (1) exist on $(-\infty,+\infty)$ if and only if there exists a complete Riemannian metric on $\mathbb{R}^{n+1}$ such that the norm of vector field $\bar{Y}^{+}$is uniformly bounded on $\mathbb{R}^{n+1}$.

Theorem 8. Let the pencil $\lambda \tilde{L}+\tilde{M}$ be regular, the characteristic polynomial satisfy the rang-degree condition and Condition 2 be fulfilled. Then all solutions of (1) exist on $(-\infty,+\infty)$ if and only if on $\mathbb{R}^{d+1}$ there exists a smooth proper function $\varphi: \mathbb{R}^{n+1} \rightarrow \mathbb{R}$ such that the absolute value $\left|\bar{Y}^{+} \varphi\right|$ of derivative of $\varphi$ in the direction of $Y^{+}$is uniformly bounded on $\mathbb{R}^{n+1}$. 
Indeed, Theorem 7 (Theorem 8) is a reformulation of Theorem 1 (Theorem 2, respectively) for system (10) on $\mathbb{R}^{n}$.

The research is made at the expense of grant of Russian Scientific Foundation (project 14-21-00066) and Voronezh State University.

\section{References}

1. Shestakov A.L., Sviridyuk G.A. A New Approach to Measurement of Dynamically Perturbed Signals. Bulletin of the South Ural State University. Series Mathematical Modelling, Programming \&6 Computer Software, 2010, no. 16 (192), issue 5, pp. 116-120. (in Russian).

2. Shestakov A.L., Sviridyuk G.A. Optimal Measurement of Dynamically Distorted Signals. Bulletin of the South Ural State University. Series Mathematical Modelling, Programming $\&$ Computer Software, 2011, no. 17 (234), issue 8, pp. 70-75.

3. Filipkovskaya M.S. On Conditions of Global Solvability of Differential-Algebraic Equations. Materials of International Conference "S.G. Krein Voronezh Winter Mathematical School - 2014", Voronezh, Voronezh State University, 2014, pp. 362-372. (in Russian)

4. Rutkas A.G., Filipkovskaya M.S. Prolongation of Solutions of a Certain Class of Differential-Algebraic Equations. Zhurnal obchislyuvalnoyi ta prikladnoyi matematyky, 2013, no. 1, pp. 135-145. (in Russian)

5. Filipkovskaya M.S. Prolongation of Solutions for a Certain Class of DifferentialAlgebraic Equations and Applications to non-linear Radio-Engineering. Visnyk of Kharkov National University. Series Mathematical Modelling, Informational Technologies and Automatic Control Systems, 2012, no. 1015, issue 19, pp. 306-319. (in Russian)

6. Gliklikh Yu.E. On Non-Local Prolongation Conditions for Integral Curves of Vector Fields. Differential Equations, 1977, vol. 12, no. 4, pp. 743-744. (in Russian)

7. Gliklikh Yu.E. Necessary and Sufficient Conditions for Global in Time Existence of Solutions of Ordinary, Stochastic, and Parabolic Differential Equations. Abstract and Applied Analysis, 2006, pp. 1-17. Article ID 39786.

8. Gliklikh Yu.E. Global and Stochastic Analysis with Applications to Mathematical Physics. London, Springer-Verlag, 2011. 460 p. DOI: 10.1007/978-0-85729-163-9

9. Chistyakov V.F., Shcheglova A.A. Izbrannye glavy teorii algebro-differentsial'nykh sistem [Selected Chapters of Differential Algebraic Equations Theory]. Novosibirsk, Nauka, 2003. 320 p.

10. Gantmakher F.R. Teoriya matrits [Theory of Matrices]. Moscow, Fizmatlit, 1967. $575 \mathrm{p}$. 


\title{
О ГЛОБАЛЬНЫХ ПО ВРЕМЕНИ РЕШЕНИЯХ ДИФФЕРЕНЦИАЛЬНО-АЛГЕБРАИЧЕСКИХ УРАВНЕНИЙ
}

\author{
Ю.Е. Гликлих
}

\begin{abstract}
Мы исследуем дифференциально-алгебраические уравнения, возникающие в математических моделях некоторых радиотехнических уствройств. Описан класс дифференциально-алгебраических уравнений, для которого доказаны необходимые и достаточные условия для глобального по времени существования решений. Как и во мнгих других работах, в которых получены достаточные условия для таких уравнений, мы сводим их к обыкновенным дифференциальным уравнениям и затем применяем необходимые и достаточные условия для последних. Мы рассматриваем системы, у которых матричный пучок регулярен и (для простоты) характеристический многочлен удовлетворяет условию ранг-степень. Мы также требуем вылнения некоторых дополнительных условий, который позволяют сводить дифференциально-алгебраические уравнения к дифференциальным.
\end{abstract}

Ключевые слова: дифференциально-алгебрачческие уравнения; глобальное существование решений; сотстверрые отображения; полная риманова метрика.

\section{Литература}

1. Шестаков, А.Л. Новый подход к измерению динамически искаженных сигналов / А.Л. Шестаков, Г.А. Свиридюк // Вестник Южно-Уральского государственного университета. Серия: Математическое моделирование и программирование. 2010. - №16 (192), вып. 5. - С. 116-120.

2. Шестаков, А.Л. Оптимальное измерение динамически искаженных сигналов / А.Л. Шестаков, Г.А. Свиридюк // Вестник Южно-Уральского государственного университета. Серия: Математическое моделирование и программирование. 2011. - № 17 (234), вып. 8. - С. 70-75.

3. Филипковская, М.С. Об условиях глобальной разрешимости дифференциальноалгебраических уравнений / М.С. Филипковская // Материалы международной конференции «Воронежская зимняя математическая школа С.Г. Крейна», 2014. - Воронеж: ВГУ, 2014. - С. 362-372.

4. Руткас, А.Г. Продолжение решений одного класса дифференциальноалгебраических уравнений / А.Г. Руткас, М.С. Филипковская // Журнал обчислювальної та прикладної математики. - 2013. - №1. - С. 135-145.

5. Филипковская, М.С. Продолжение решений полулинейных дифференциальноалгебраических уравнений и приложения в нелинейной радиотехнике / М.С. Филипковская // Вісник ХНУ ім. В.Н. Каразіна. Серия: Математичне моделювання. Інвормаційні технології. Автоматизовані системи управління. - 2012. - № 1015, вип. 19. - С. 306-319.

6. Гликлих, Ю.Е. Об условиях нелокальной продолжимости интегральных кривых векторных полей // Дифференциальные уравнения. - 1977. - Т. 12, №4. C. $743-744$. 
7. Gliklikh, Yu.E. Necessary and Sufficient Conditions for Global in Time Existence of Solutions of Ordinary, Stochastic, and Parabolic Differential Equations / Yu.E. Gliklikh // Abstract and Applied Analysis. - 2006. - Article ID 39786. - P. 1-17

8. Gliklikh, Yu.E. Global and Stochastic Analysis with Applications to Mathematical Physics / Yu.E. Gliklikh. - London: Springer-Verlag, 2011. - 460 p.

9. Чистяков, В.Ф. Избранные главы теории алгебро-дифференциальных систем / В.Ф. Чистяков, А.А. Щеглова. - Новосибирск: Наука, 2003. - 320 с.

10. Гантмахер, Ф.Р. Теория матриц / Ф.Р. Гантмахер.- М: Физматлит, 1967. - 575 с.

Исследование выполнено за счет гранта Российского Научного Фонда (проект №14-21-00066) и Воронежсккого государственного университета.

Юрий Евгеньевич Гликлих, доктор физико-математических наук, профессор, кафедра «Алгебра и топологические методы анализа», Воронежский государственный университет, (г. Воронеж, Российская Федерация), yeg@math.vsu.ru.

Поступила в редакиию 23 апреля 2014 г. 